\title{
Treatment of protrusion of Lumbar Intervertebral Disc (LID) with percutaneous laser disc decompression - a follow-up study of 108 patients
}

\author{
Jirong $\mathrm{ZHAO}^{1}$, Min $\mathrm{SHI}^{2}$, Xingsheng WANG ${ }^{3 *}$ (D), Ning $\mathrm{ZHAO}^{1}$, Qiang DENG ${ }^{1}$, Qiqing $\mathrm{CHEN}^{1}$, Yanjun $\mathrm{ZHANG}^{1}$, \\ Wen $\mathrm{CHEN}^{1}$, Huanping $\mathrm{ZHU}^{1}$
}

\begin{abstract}
To study the long-term clinical efficacy of protrusion of lumbar intervertebral disc with percutaneous laser disc decompression (PLDD). A statistics was conducted on 108 patients who had been treated with percutaneous laser disc decompression, the intervertebral height of related lesion spaces of patients in different time points after treatment and the intervertebral height ratio was calculated respectively; moreover, a statistics was conducted on VAS evaluation of patients in different time points, and the long-term efficacy after treatment with percutaneous laser disc decompression was evaluated with statistical method. The patients with follow-up period after operation respectively up to 5, 8 and 10 years and those in 3 years after operation were analyzed statistically in intervertebral height ratio and VAS scoring, and the difference was without significant statistical significance. Single-factor was analyzed to the factors likely to influence the effect of operation to get the authenticity of influence of age, disease duration and disease stage on the postoperative efficacy. Percutaneous laser disc decompression was featured by safety, efficacy and fewer complications in treatment of protrusion of lumbar intervertebral disc, and also it had no obvious influence on the spinal stability, and long-term postoperative efficacy was stable.
\end{abstract}

Keywords: percutaneous laser disc decompression (PLDD); treatment; protrusion of lumbar intervertebral disc; VAS (Visual Analogue Scale/Score); curative effect analysis.

Practical Application: Percutaneous laser disc decompression is safe, effective, and has fewer complications. It can be considered for the treatment of lumbar disc herniation.

\section{Introduction}

Protrusion of lumbar intervertebral disc is a common clinical disease and frequently-occurring disease in Orthopedics Department. It is one of common reasons resulting in pain in waist and lower extremities, which is manifested as lumbar pain accompanied with or without lower limb ache and numb, even causing nerve root or cauda equina dysneuria (Radulović et al., 2004), and it is hard to be cured unless otherwise it is treated surgically with a higher recurrence rate. Various kinds of operative treatment are likely to cause different levels of cause trauma and hemorrhage, more complications, and that lumbar stability is easy to be influenced after operation (Dionsio et al., 2020; Ismail et al., 2020; Valença et al., 2021). Percutaneous laser disc decompression (PLDD) (Xiao et al., 2004) is a kind of technology used for minimally invasive therapy of spine between conservative treatment and operative treatment. A slender light-guide fiber will be used during the treatment process for generating pulse laser, which vaporizes some nucleus pulposus of the prominent intervertebral disc, relieves or eliminates the oppress and stimulation of neural so as to realize the treatment purpose of improving the symptoms. This technology was applied by Choy and Ascher (Tassi et al., 2010) in clinical treatment of protrusion of lumbar intervertebral disc successfully for the first time in 1986, and with the advantages like high safety and simple operation, it became one of main means used for treatment of protrusion of lumbar intervertebral disc quickly. The effective rate of such minimally invasive technology across the world has reached 70\%-89\% (Ren et al., 2013). There are more clinical and experimental researches on treatment of protrusion of lumbar intervertebral disc with PLDD in recent years. Brouwer et al. (2009) conducted randomized controlled trial on patients with protrusion of lumbar intervertebral disc treated with PLDD and conventional open operation, showing that PLDD had a clear clinical efficacy in treatment of protrusion of lumbar intervertebral disc. However, Vijay et al.(Singh et al., 2013), through literature review and clinical observation, held that, the reporting of systematic research on long-term efficacy evaluation and influencing factors was lacked when PLDD was used for treating protrusion of lumbar intervertebral disc. Retrospective analysis were conducted on 108 cases of patients with protrusion of lumbar intervertebral disc treated with PLDD and getting effective follow-up visits in the period from April 2003 to December 2013, the long-term efficacy of PLDD in treatment of protrusion of lumbar intervertebral disc was evaluated: 


\subsection{Clinical data}

108 patients with protrusion of lumbar intervertebral disc, including: 71 men and 37 women, aging from 12 60, averagely 37.84 years old, course of disease: 3 days to 10 years. 12 patients among them had the clinical symptom of simple waist pain, 77 patients felt waist pain accompanied with unilateral lower limb pain and numbness, 19 patients suffered from waist pain accompanied with double lower limb pain and numbness, and 12 patients felt pure waist pain only. They were diagnosed as the patients with protrusion of lumbar intervertebral disc at different stage, including 50 in the stage L4-5, 30 in the state L5-S1, and 2 in the stages of L3-4 and L4-5, and 26 in the stages of L4-5, L5-S1.

\section{Materials and methods}

\subsection{Equipment and devices}

$800 \mathrm{~mA}$ digital X-ray machine, a semiconductor laser therapy apparatus, produced by Shanghai Gaopin Medical Laser Technology Development Co., Ltd., wavelength 80/nM, maximum output power $10 \mathrm{~W}$, pulse output, pulse width $4.5 \mathrm{~ns}$, frequency $2.5 \mathrm{~Hz}$, optical diameter $600 \mathrm{um}, 16 \mathrm{G} \times 15 \mathrm{~cm}$.

\subsection{Operation method}

A patient was in prone position under electrocardiogram monitoring with abdominal pad up to about $15 \mathrm{~cm}$ high, and metal X-ray perspective positioner was placed in the lesion gap, a puncture site for posterolateral approach was taken, an aseptic towel was paved for conventional skin disinfection, $50 \mathrm{~mL} \mathrm{1 \%}$ lidocaine was taken for local infiltration anesthesia, $16 \mathrm{G} \times 15 \mathrm{~cm}$ puncture needle was used to puncture via skin layer by layer slowly to reach intervertebral disc in disease stage, and X-ray positive lateral perspective was adopted to determine that the puncture needle was in the rear $1 / 3$ of intervertebral space, then laser vaporization therapy was conducted to this patient with parameters including laser output power: $10 \mathrm{~W}$ and pulse time and pulse interval time: 1 s. The optical fiber diameter was $600 \mu \mathrm{M}$, and the optical fiber was greater than $3 \mathrm{~mm}$ beyond the needle core. The total laser amount was set as 3000 4000 J. It's required to pay attention to the patient's reaction and inquire the patient's own feeling in the process of vaporization, if the patient had any abnormal feeling like waist or lower limb swelling pain, laser output should be stopped immediately, gas suction was needed, the optical fiber and needle tip length and direction should be adjusted, and laser vaporization would be ended when set energy was reached through vaporization, then optical fiber and puncture needle should be pulled out, and the needle eye place should be covered with aseptic dressing. This study followed the tenants of the Declaration of Helsinki. The protocol was approved by the Ethics Committee of author's hospital.

\subsection{Postoperative treatment}

The patient was advised to stay in bed for $24 \mathrm{~h}$ after operation to make the lumbar vertebral space reduce and facilitate the intercalated disc edema fade away and retract; the patient could walk on the floor for exercise under the protection of waist protector 24 hours later, and increase the physical activity level gradually; the patients was guided to have functional exercise of five-point type and fly-bird type 3 days after operation; the patient could leave hospital and go home for recuperation $3 \sim 5$ days after operation.

\subsection{Evaluation criteria}

Intervertebral height evaluation: Intervertebral height was measured according to lumbar vertebra lateral X-ray film according to the Mochidas (Yorimitsu et al., 2001) reported by literatures. The ligature of diagonal intersection of upper and lower vertebrae of the measured intervertebral space was extended upwards on the lumbar vertebra lateral X-ray film, and also crossed with the connecting line of front top angle and rear top angle of previous centrum, and the place of this line segment inside the upper vertebral body was $A$, and the place of this line segment inside the intervertebral space was a, and then the length between $\mathrm{A}$ and a was measured, and the ratio of $\mathrm{a}$ and $\mathrm{A}$ was calculated, marked as R.

\subsection{Statistical treatment}

A database was established with the intervertebral height ratio and VAS scoring of patients of follow-up visiting as data, and it was expressed with mean \pm standard deviation. (Table 1) Chi-square test (x2) was conducted to data by use of SPSS 19.0, with the result as shown in Table 2 . To facilitate the analysis of

Table 1. VAS Scoring.

\begin{tabular}{cc}
\hline Score & Symptom \\
\hline 0 & Anodynia \\
$<3$ & Slight pain, tolerable \\
$4-6$ & Painful and sleep disorders, tolerable \\
$7-10$ & Increasingly strong pain, intolerable, inappetence and \\
& sleep disorders \\
\hline
\end{tabular}

Table 2. Comparison of intervertebral height and VAS scoring before and after operation.

\begin{tabular}{|c|c|c|c|}
\hline Time & $\begin{array}{c}\text { Case } \\
\text { visited }\end{array}$ & $\begin{array}{c}\text { Intervertebral } \\
\text { height }(\mathrm{IH})(\mathrm{cm})\end{array}$ & VAS Score \\
\hline Preoperative & (a) 108 & (b) $0.342 \pm 0.005$ & (c) $6.3 \pm 2.0$ \\
\hline $\begin{array}{l}\text { Postoperative } \\
6 \text { months }\end{array}$ & (d) 101 & (e) $0.334 \pm 0.012$ & (f) $1.0 \pm 1.2^{*}$ \\
\hline $\begin{array}{c}\text { Postoperative } \\
3 \text { years }\end{array}$ & (g) 93 & (h) $0.321 \pm 0.009$ & (i) $1.9 \pm 1.1^{*}$ \\
\hline $\begin{array}{c}\text { Postoperative } \\
5 \text { years }\end{array}$ & (j) 84 & (k) $0.312 \pm 0.008 \#$ & (l) $2.5 \pm 1.0^{\#}$ \\
\hline $\begin{array}{c}\text { Postoperative } \\
8 \text { years }\end{array}$ & (m) 50 & (n) $0.297 \pm 0.017 \#$ & (o) $2.4 \pm 1.9 \#$ \\
\hline $\begin{array}{c}\text { Postoperative } \\
10 \text { years }\end{array}$ & (p) 46 & (q) $0.288 \pm 0.013 \#$ & (r) $2.9 \pm 1.4 \#$ \\
\hline
\end{tabular}

*The value compared with that before operation was of statistical significance $(\mathrm{P}<0.05)$; \#The value compared with that 3 years after operation was of no statistical significance $(\mathrm{P}>0.05)$. 
Table 3. Effect of operation satisfaction evaluation with improved Macnab standard (Le et al., 2003).

\begin{tabular}{cl}
\hline Level & \multicolumn{1}{c}{ Effect } \\
\hline Excellent & $\begin{array}{l}\text { Elevation test of straight leg }>70^{\circ} \text {, the patient had the } \\
\text { pain fade away without being limited in movement } \\
\text { function, and could recover his } / \text { her work and life; }\end{array}$ \\
Good & $\begin{array}{l}\text { Elevation test of straight leg }>70^{\circ} \text {, the patient' pain } \\
\text { obviously improved, which was still not serious, but } \\
\text { influencing work; }\end{array}$ \\
Fair & $\begin{array}{l}\text { Elevation test of straight leg }<70^{\circ}, \text { and the patient } \\
\text { still had a pain or was limited in movement; }\end{array}$ \\
Poor & $\begin{array}{l}\text { The patient had no improvement or got aggravated } \\
\text { in postoperative elevation test of straight leg and } \\
\text { symptom (the excellence ratio }=\text { total sum of } \\
\text { excellent cases: total cases). }\end{array}$ \\
\hline
\end{tabular}

Table 4. Single-factor analysis of factors influencing the postoperative efficacy.

\begin{tabular}{|c|c|c|c|c|c|}
\hline \multirow{2}{*}{ Influence factor } & \multirow{2}{*}{ Level } & \multicolumn{2}{|c|}{$\begin{array}{c}\text { Effectiveness after } \\
\text { operation }\end{array}$} & \multirow{2}{*}{$2 x$} & \multirow[t]{2}{*}{$\mathrm{P}$} \\
\hline & & Good (\%) & Poor (\%) & & \\
\hline \multirow[t]{2}{*}{ Age (year) } & $\geq 40$ & $39(82.98)$ & $8(17.02)$ & 8.436 & 0.003 \\
\hline & $<40$ & $57(93.4)$ & $4(6.56)$ & & \\
\hline \multirow[t]{2}{*}{ Gender } & Male & $63(88.77)$ & $8(11.23)$ & 4.936 & 0.026 \\
\hline & Female & $32(86.49)$ & $5(13.51)$ & & \\
\hline \multirow{2}{*}{$\begin{array}{l}\text { Disease duration } \\
\text { (year) }\end{array}$} & $\geq 1$ year & $36(78.26)$ & $9(21.74)$ & 9.471 & 0.002 \\
\hline & $<1$ year & $56(91.80)$ & $5(8.20)$ & & \\
\hline \multirow{2}{*}{$\begin{array}{l}\text { Lesion scope } \\
\text { (pcs) }\end{array}$} & 1 & $73(91.25)$ & $7(8.75)$ & 8.009 & 0.003 \\
\hline & $>1$ & $22(78.57)$ & $6(21.43)$ & & \\
\hline
\end{tabular}

influencing factors, therapeutic evaluation was classified into two types, and those evaluated as Excellent and Good according to Macnab standard would be deemed to have a good therapeutic effect, and those evaluated as Fair and Poor would be deemed to have a poor therapeutic effect. (Table 3) Age, gender, disease duration and lesion segment were included into the influencing factors, and single factor analysis was conducted through x2 inspection, $P$ value $<0.05$ was of statistical significance, with the result as shown in Table 4.

\section{Results}

\subsection{Comparison of results before and after operation}

Patient: Liu ${ }^{*}$, Female, 47. Came to see a doctor for waist pain and discomfort for more than 1 year, through examining the lumbar by CT, it was shown that the L5-S1 intervertebral disc had pot base type of obvious herniation. The patient was treated through PLDD after comprehensive examination, and the patient felt obvious pain in the waist and the transference cured 3 weeks later after staying in bed. See the Figure 1-4 as follows:

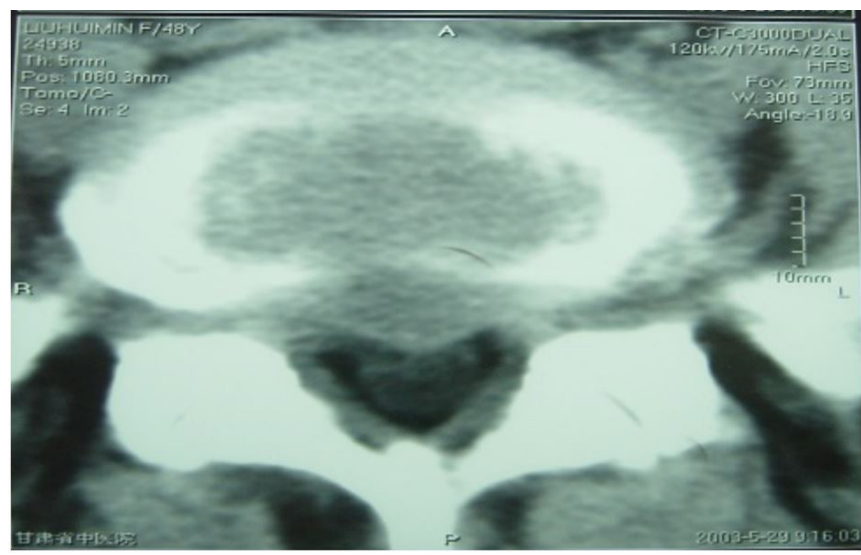

Figure 1. CT showed that: LDH, L5-S1 had herniation before operation (May-2003).

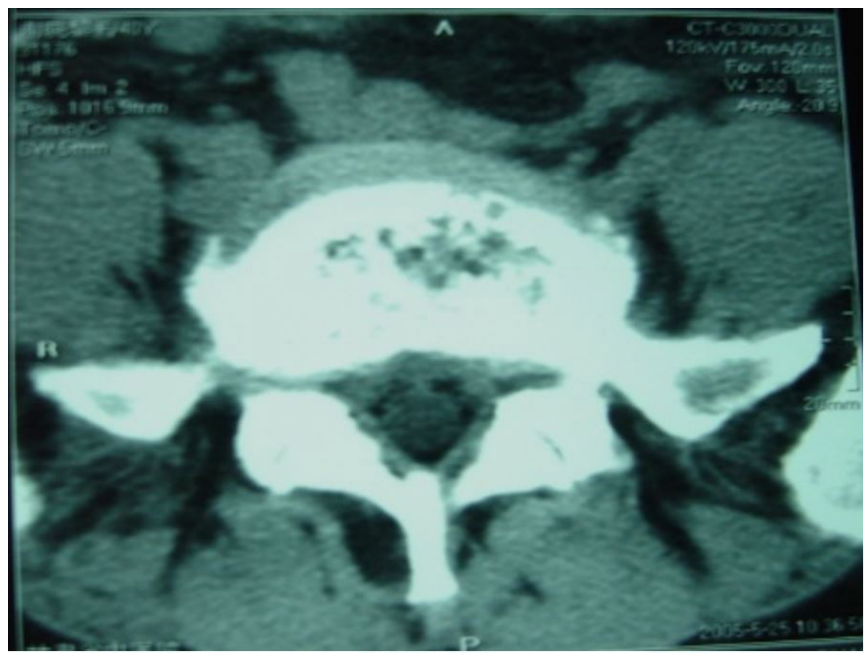

Figure 2. CT showed that: L5-S1 herniation recovered through reexamination 24 months after operation (May-2005).

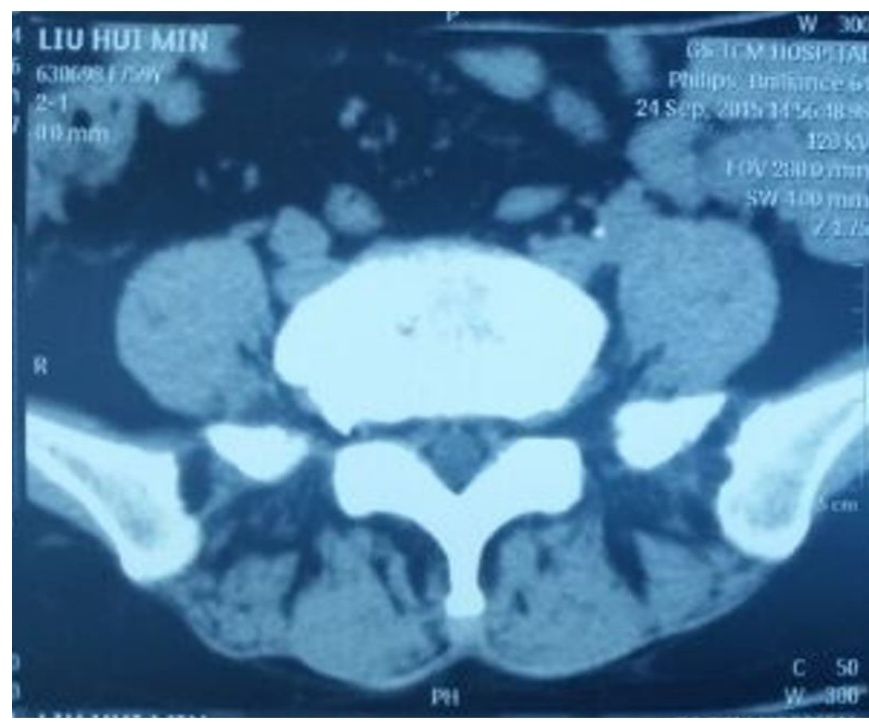

Figure 3. CT showed that: L5-S1 herniation recovered stably through reexamination 12 years after operation (September-2015). 


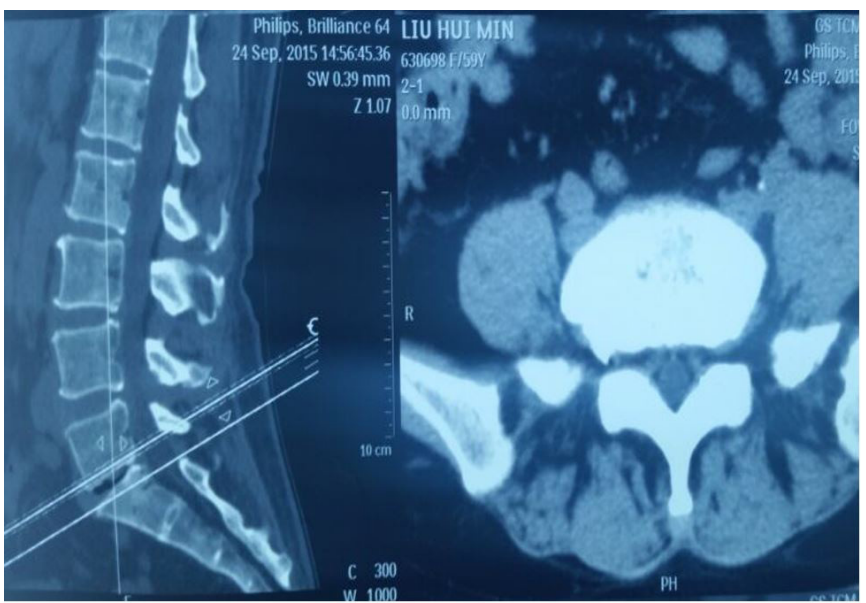

Figure 4. CT showed that: L5-S1 herniation recovered stably through reexamination 12 years after operation.

\section{Discussion}

\subsection{Long-term clinical efficacy after operation of PLDD}

Protrusion of lumbar intervertebral disc is a common disease and frequently- occurring disease in Orthopedics Department, and there are various methods to treat this disease, however, the long-term efficacy stability of different methods of treatment is unclear. As open surgical decompression has the disadvantages like damage to normal stability of spine, many percutaneous minimally invasive interventional techniques have appeared for the purpose of realizing intervertebral disc decompression. Minimally invasive technique had been develop and applied rapidly for its advantage that it can better preserve the spinal structure, reduce the soft tissue destruction, and has lower surgical risks. The treatment of protrusion of lumbar intervertebral disc with PLDD is to "cut" a part of the protruding intervertebral disc nucleus mainly through percutaneous puncture technique and by use of high-energy local biological effect (Zhao et al., 2011) of laser, so as to reduce the internal pressure of diseased disc, reduce and retract the protruding disc tension, and further to alleviate or relieve the compression to nerve root, and relax the compressed nerve root, therefore, fundamentally relieving the clinical symptoms of patients with protrusion of lumbar intervertebral disc and eliminating the patients' clinical symptoms like waist and leg pain, numbness or dyskinesia, to reach the purpose of treatment (Chiu et al., 2000). In addition, the biological activation reaction of laser also may help to reduce the secretion of pain-caused materials, promote the angiectasis, improve the immune function and normalize the autonomic nervous function, so as to achieve the purpose of relieving pain and inflammation of diseased region (Choy et al., 1992).

Intervertebral disc height is a known parameter with significant correlation with degeneration of lumbar intervertebral disc (Cyteval et al., 2006). It is verified by related scholars through related experiments and clinical studies that: the irreversible loss of intervertebral disc height is related to the reduction of intervertebral disc tissue volume, and the intervertebral disc space narrowing has been caused inevitably by the degeneration and denaturation of intervertebral disc (Brinckmann \& Grootenboer, 1991). Therefore, as to the various treatment methods, long-term maintenance of intervertebral height is of great significance for evaluation of the effectiveness of a treatment method (Li et al., 2007). In this paper, through follow-up visit to the patients with protrusion of lumbar intervertebral disc treated with PLDD, their intervertebral height was measured at different time points, and the result showed that, with the increase of time, the intervertebral height showed a trend of decline, and this kind of tendency was considered to be related with the degeneration of human body itself. Through statistical analysis, it's discovered that the comparison of intervertebral height in postoperative 10 years and the intervertebral height in postoperative 5 years and 8 years was of no significant statistical significance $(P>0.05)$, indicating that the intervertebral height after treatment was relatively stable in long-term change, which provided a basis for maintenance of long-term clinical efficacy. It's discovered in the follow-up visit process, the patients with poor postoperative efficacy all had a significantly reduced intervertebral height 3 years later, and then suffered lumbar instability, proliferation, spinal stenosis, protrusion of intervertebral disc of original stage or adjacent stages. Through the analysis on the results of treated patients' waist and leg pain scoring, it's discovered that, the comparison of patients before operation and 6 months and 3 years after operation was of statistical significance $(P<0.05)$, and the comparison of pain in waist and leg of the patients who had been operated for 5 years, 8 years and 10 years and those who have been operated for 3 years was without significant statistical significance $(P>0.05)$. This indicated that, when protrusion of intervertebral disc was treated with PLDD, the postoperative short-term symptom was improved obviously, and also there was a stable long-term efficacy. Through the long-term follow-up visit, we discovered that, with the extension of postoperative time, some patients had the uncomfortable symptoms like slight soreness of waist after excessive sitting or fatigue, and the symptoms would disappear after rest, and this was possibly related with the overall degenerative change of lumbar vertebra. It was proved by continuous study and observation that: PLDD used for treating the protrusion of lumbar intervertebral disc was featured by safety, efficiency and few complications, and also it had no significant influence on the spinal stability, and the spine had a better long-term stability, and moreover, the postoperative medium and long-term symptom improvement was obvious and the treatment effect was stable; therefore, PLDD was worth of application in clinical treatment.

Damaged annulus fibrosus repair is a tough problem, and also one of main reasons frequently resulting in the re-protrusion. No matter through open operation or minimally invasive surgery, although the protruding nucleus pulposus is excised, annulus fibrosus (AF) fracture still exists. It is still the main problem on how to repair the damaged AF for preventing the re-protrusion and maintaining the long-term efficacy. It was discovered in clinical application that PLDD had a better effect of treatment on inclusive protrusion of lumbar intervertebral disc. After we attempted to use palliative PLDD therapy for the patients with a bigger protrusion, these patients had their symptoms obviously alleviated, and in the long-term follow-up visit, it's discovered that, their protruding nucleus pulposuses were returned, and also MRI 
showed that the damaged AFs were gradually healed, indicating that laser vaporization had an active effect on the damaged AF repair; therefore, it's speculated that, annulus fibrosus cells were perceptive to mechanical stimulation and laser photothermal stimulation, and under this perceptual stimuli, many cellular factors reached the purpose of cell proliferation and PG synthesis; therefore, repairing the damaged intervertebral disc.

\subsection{Related factors influencing the treatment of LID with PLDD}

To facilitate the analysis on influencing factors of treatment with PLDD, therapeutic evaluation was conducted according to Macnab criteria, and those evaluated as Excellent and Good were regarded to have a good therapeutic effect and those evaluated as Fair and Poor were regarded to have a poor therapeutic effect. Age, gender, lesion segment and disease duration were included into the influencing factors for analysis. Single-factor analysis was conducted. The result showed that: age, disease duration and lesion segment had an influence on postoperative efficacy $(\mathrm{P}<0.05)$, and gender had no significance influence on postoperative efficacy $(\mathrm{P}>0.05)$, as shown in Table 4 . It could be seen from the single-factor statistical analysis result that, age, disease duration and lesion segment quantity had a certain influence on PLDD postoperative efficacy, and the patients who were below 40 years old, had a disease duration of less than one year, and (or) suffered single-segment intervertebral disc disorder were superior to those that were above 40 years old, had a disease duration of more than one year and (or) suffered multi-segment intervertebral disc disorder in postoperative signs and symptoms improvement. The increase of patient's age would become a factor causing the decline of postoperative efficacy. In the patient cases treated in this paper, those below 40 years old had the excellence ratio after treatment up to $93.4 \%$, obviously higher than that of those above 40 years old, and the author considered that this was related to the denaturation of intervertebral disc, reduction of nucleus pulposus moisture, protrusion calcification or adhesion with surrounding tissues, ligamentum flavum hypertrophy and zygopophysis hyperplasia and cohesion with the increase of age, and as to these patients, we would conduct individualized assessment through CT and MRI, in order to make clear their adaptability to PLDD. Cheng Jieping (Cheng et al., 2004) conducted 1 12 months' follow-up visit to 221 cases of patients with protrusion of lumbar intervertebral disc treated by PLDD, and concluded that through statistics: those aged 17 40 years old had the postoperative excellence ratio up to $98.4 \%$, those aged $41 \sim 60$ years old had the postoperative excellence ratio $85.7 \%$, and those above 61 years old had the postoperative excellence ratio $73.7 \%$; the therapeutic effect was significantly different between those aged 17 40 years old and the old patients, and this was consistent with the statistical result given by the author. Through statistical analysis, the patients with a shorter disease duration before operation had a better postoperative efficacy, and this could because that, as to a patient with a longer disease duration, his/her partial ligament and protruding nucleus pulposus tissue of lumbar vertebra were calcified, with a reduced elasticity, which was not favorable to nucleus pulposus return, while a patient with a shorter disease duration has his/her posterior longitudinal ligament and annulus fibrosus elasticity be in good situation, with a bigger reaction force action, which could promote the protruding nucleus pulposus return. The number of lesion segments was also one of factors influencing the postoperative efficacy. In this paper, the patients with single and multiple lesions of intervertebral disc treated were analyzed statistically, and the result showed that, the patients with single lesion segment was superior to those with multiple lesions in postoperative efficacy, and it was considered that, with the increase of lesion segments, intervertebral height and internal stability would be influenced greatly, and the change of mechanical structure of lumbar spine was caused gradually after operation, and finally, the maintenance of postoperative efficacy was caused, and even repeated symptoms could be caused. In the follow-up visit process hereof, 8 patients had a poor postoperative efficacy, 5 patients were above 40 years old, 3 patients had the disease duration lasting for one year, and 3 patients accepted the treatment of two stages at the same time. Therefore, before the patients with protrusion of lumbar intervertebral disc were treated with PLDD, strict individualized analysis was needed, so as to strictly grasp the indications and guarantee the postoperative efficacy. Certainly, the factors influencing the treatment of protrusion of lumbar intervertebral disc with PLDD are complicated, and the clinical cases in this study are fewer and also the follow-up visit indicators are single, and more samples are needed for analysis and research, so as to make clear more factors influencing the postoperative efficacy and the degree of influence, therefore, providing a reliable basis for clinical treatment.

\section{Conclusion}

In conclusion, PLDD is one of the effective means for treating the protrusion of lumbar intervertebral disc between the conservative treatment and open operation, it has a significant treatment effect and stable long-term therapeutic effect, so it is worthy of popularization and application in clinics. As there are many factors influencing its therapeutic effect, it is required to strictly grasp the indications in the process of treatment, so as to guarantee the improvement of postoperative efficacy of patients, therefore, bringing about a greater benefit to the board patients with protrusion of lumbar intervertebral disc.

\section{Ethical approval}

The protocol was approved by the Ethics Committee of Gansu Provincial Hospital of Traditional Chinese Medicine.

\section{Conflict of interest}

The author declare that they have no conflict of interest.

\section{References}

Brinckmann, P., \& Grootenboer, H. (1991). Change of disc height, radial disc bulge, and intradiscal pressure from discectomy. An in vitro investigation on human lumbar discs. Spine, 16(6), 641-646. http:// dx.doi.org/10.1097/00007632-199106000-00008. PMid:1862403.

Brouwer, P. A., Peul, W. C., Brand, R., Arts, M. P., Koes, B. W., Berg, A. A., \& Buchem, M. A. (2009). Effectiveness of percutaneous laser disc decompression versus conventional open discectomy in 
the treatment of lumbar disc herniation; design of a prospective randomized controlled trial. BMC Musculoskeletal Disorders, 10(1), 49. http://dx.doi.org/10.1186/1471-2474-10-49.

Cheng, J., Yang, Y., \& Ren, X. (2004). Comparison of different age groups in efficacy of percutaneous laser in treatment of protrusion of lumbar intervertebral disc. Zhongguo Jizhu Jisui Zazhi, 14, 114-116.

Chiu, J. C., Clifford, T. J., Greenspan, M., Richley, R. C., Lohman, G., \& Sison, R. B. (2000). Percutanneous microdecompressive erddoscopic cervical disctomy with laser the rmodiskoplasty. Mount Sinai Journal of Medicine, 67, 278-282.

Choy, D. S., Ascher, P. W., Ranu, H. S., Saddekni, S., Alkaitis, D., Liebler, W., Hughes, J., Diwan, S., \& Altman, P. (1992). Percutaneous laser disc decompression. A new therapeutic modality. Spine, 17(8), 949-956. http://dx.doi.org/10.1097/00007632-199208000-00014. PMid:1387977.

Cyteval, C., Fescquet, N., Thomas, E., Decoux, E., Blotman, F., \& Taourel, P. (2006). Predictive factors of efficacy of periradicular corticosteroid injections for lumbar radiculopathy. AJNR. American Journal of Neuroradiology, 27(5), 978-982. PMid:16687527.

Dionsio, A. P., Silva, M., Carioca, A., Adriano, L. S., Abreu, F. A. P., Wurlitzer, N. J., Pinto, C. O., \& Pontes, D. F. (2020). Effect of yacon syrup on blood lipid, glucose and metabolic endotoxemia in healthy subjects: a randomized, double-blind, placebo-controlled pilot trial. Food Science and Technology, 40(1), 194-201. http://dx.doi. org/10.1590/fst.38218.

Ismail, G. A., Gheda, S. F., Abo-Shady, A. M., \& Abdel-Karim, O. H. (2020). In vitro potential activity of some seaweeds as antioxidants and inhibitors of diabetic enzymes. Food Science and Technology, 40(3), 681-691. http://dx.doi.org/10.1590/fst.15619.

Le, H., Sandhu, F. A., \& Fessler, R. G. (2003). Clinical outcomes after minimal access surgery for recurrent lumbar disc hemination. Neurosurgical Focus, 15(3), E12. http://dx.doi.org/10.3171/ foc.2003.15.3.12. PMid:15347230.

Li, Y., Tao, W., \& Yong, X. (2007). Change of Facet Joint of Lumbar Vertebra Joint and Intervertebral Space Height after Operation of Percutaneous Laser Disc Decompression. Zhongguo Jizhu Jisui Zazhi, 17(7), 524-524.

Radulović, D., Tasić, G., Joković, M., \& Nikolić, I. (2004). The role of surgical decompression of lauda equine in lumbar disc herniation and recovery of bludder function. Medicinski Pregled, 57(7-8), 327330. http://dx.doi.org/10.2298/MPNS0408327R. PMid:15626287.

Ren, L., Guo, H., Zhang, T., Han, Z., Zhang, L., \& Zeng, Y. (2013). Efficacy evaluation of percutaneous laser disc decompression in the treatment of lumbar disc herniation. Photomedicine and Laser Surgery, 31(4), 174-178. http://dx.doi.org/10.1089/pho.2012.3402. PMid:23565889.

Singh, V., Manchikanti, L., Calodney, A. K., Staats, P. S., Falco, F. J., Caraway, D. L., Hirsch, J. A., \& Cohen, S. P. (2013). Percutaneous lumbar laser disc decompression: an update of current evidence. Pain Physician, 16(Suppl. 2), SE229-SE260. http://dx.doi.org/10.36076/ ppj.2013/16/SE229. PMid:23615885.

Tassi, G. P., Choy, D. S., Hellinger, J., Hellinger, S., \& Lee, S. H. (2010). Percutane-ous Laser Disc Decompression (PLDD): experience and results from multiple centers and 19880 procedures. AIP Conference Proceedings, 1226, 69-76. http://dx.doi.org/10.1063/1.3453789.

Valença, L. M., Paiva, J. D. E. D., Barbosa, S. B. P., Pinheiro, I. O., Batista, Â. M. V., Silva, M. J. F. B. D., \& Medeiros, E. S. D. (2021). Evaluation of residues of $\beta$-lactam, sulfonamide, tetracycline, quinolone, fluoroquinolone e pyrimidine in raw milk. Food Science and Technology, 41(3), 603-606. http://dx.doi.org/10.1590/fst.23520.

Xiao, Y., Dan, P., \& Li, Y. (2004). Treatment of protrusion of lumbar intervertebral disc with percutaneous Laser Disc Decompression. Zhongguo Jizhu Jisui Zazhi, 14(5), 301-302.

Yorimitsu, E., Chiba, K., Toyama, Y., \& Hirabayashi, K. (2001). Longterm outcomes of standard discectomy for lumbar disc herniation: a follow-up study of more than 10 years. Spine, 26(6), 652-657. http:// dx.doi.org/10.1097/00007632-200103150-00019. PMid:11246379.

Zhao, J., Zhu, H., \& Chen, W. (2011). 216 cases with protrusion of Lumbar Intervertebral Disc through percutaneous Laser Disc Decompression. Chinese Journal of Laser Medicine \& Surgery, (01), 33-36. 